\title{
Current State of Knowledge - based Systems Used in Architecture, Engineering and Construction
}

\author{
Tomáš Mandičák ${ }^{1}$, Annamária Behúnová ${ }^{2}$, Peter Mésároš ${ }^{1}$, Lucia Knapčíková ${ }^{3}$ \\ ${ }^{1}$ Technical University of Košice, Institute of Construction Technology and Management at the Faculty of Civil \\ Engineering, Vysokoškolská 4, 04200 Košice, Slovakia, \\ ${ }^{2}$ Technical University of Košice, Faculty of Mining, Ecology, Process Control and Geotechno- \\ logy, Institut of earth sources, Letná 9, 04001 Košice, Slovakia \\ ${ }^{3}$ Technical University of Košice, Faculty of Manufacturing Technologies with the seat in Prešov, Bayerova 1, \\ 08001 Prešov, Slovakia
}

\begin{abstract}
Architecture, Engineering and Construction or generally construction industry has recently been characterized by increased requirements for information and communication technologies and knowledge systems. All participants of a construction project, from architect through contractor to investor require a high level of automatization. This results in pressure and increased demand for the use of knowledge systems that streamline these processes. This research discusses the issue of the knowledgebased system used in architecture, engineering and construction field. The main aim of the research was to analyze knowledge-based systems used in architecture, engineering and construction and find the overview of exploitation level in this construction sector. The research sample includes all significant participants of the construction project from designer to investor. All research samples were tested by statistical tests and all the data coming from the construction project are realized in Slovakia.
\end{abstract}

Keywords - Knowledge-based systems, construction industry, architecture, costs, construction project

DOI: 10.18421/TEM92-39

https://doi.org/10.18421/TEM92-39

Corresponding author: Lucia Knapčíková,

Technical University of Košice, Faculty of Manufacturing

Technologies with the seat in Prešov.

Email: lucia.knapcikova@tuke.sk

Received: 26 March 2020.

Revised: 08 May 2020.

Accepted: 12 May 2020.

Published: 27 May 2020.

(c))BY-NC-ND (C) 2020 Lucia Knapčíková at al; published by UIKTEN. This work is licensed under the Creative Commons Attribution-NonCommercial-NoDerivs 4.0 License.

The article is published with Open Access at www.temjournal.com

\section{Introduction}

Today, the construction industry faces major challenges and at the same time there is pressure to reduce investment. Designers and civil engineers themselves are also entering this challenging process which must adhere to the standards and specifics of the construction industry [1].

On the one hand, there are the materials used and their production. There are also the materials themselves and their properties. This also applies to working conditions (quality materials, better work with them) [2]. On the other hand, there is saving money by efficient management [3]. Knowledge technology and systems are the solution that can be used in architecture, engineering and construction (AEC). Knowledge technologies can be helpful at every stage in the construction industry, from designing, producing materials, applying and building construction, to building management and maintenance systems. It can also be beneficial for each participant in construction projects, namely from the investor, through the architect and designer, the contractor to the user and the building manager.

\section{Problem Statement}

Information and communication technology and systems are beneficial for users in every field. Generally, it has a lot of advantages. On the one hand, there is productivity increasing. On the other side, there is cost reducing of construction projects [4]. Some of our researches show that knowledge is more necessary in a construction project than only information. The term 'knowledge' is different from the terms of data and information. Generally, knowledge represents or includes facts, skills and rules accumulated over a period of time [5]. Knowledge is understood as a variable system with the interaction of facts, relationships, experiences, 
ideas and meanings [6]. Construction project management requires knowledge in the field. Knowledge is a significant capital of every company. This is particularly true at present when there is a significant paradigm shift into an industrialized and knowledge society. Knowledge should be systematically collected, protected, archived, updated and exploited. It must be constantly supplemented. For this purpose, tools are used to create and transfer knowledge. The increasing importance of knowledge, often also referred to as a critical source of business, has led businesses to work systematically in acquiring, storing and sharing knowledge, which is knowledge management [7]. It is also important to look at the ways of sharing and exchanging knowledge between the participants in the construction project. Knowledge management can be assessed. This phenomenon is recorded in construction companies as well as among users in the supply chain [8], [9].

Knowledge management is a process of identifying, but also optimizing and managing the company's intellectual property. It is all for the purpose of creating value. Another goal is to increase productivity and profitability. All this leads to the maintenance of a competitive advantage [10], [11]. The impact of the evolving knowledge economy is the realization of one fact. The fact is that the main business problem is knowledge management. This also has an impact on success, where the company's know-how is becoming increasingly important than traditional sources of economic power [12]. Knowledge Management Process is universal for any business or project. The knowledge management process has six basic steps. These are the following steps: collecting, arranging, summarizing, analyzing, merging and deciding [13]. Knowledge Management Systems (KMS) are information systems that facilitate organizational learning by storing knowledge and ensuring its availability to people (employees) as needed. These systems serve to "integrate" knowledge in an organization. Their primary task is to preserve, share and use knowledge more effectively. The basic idea of knowledge systems is to enable all participants to have access to all official knowledge, facts, documents, sources of information and subsequent solutions. Knowledge technologies are technologies that integrate important information and transform it into knowledge. The basis is a knowledge database. Knowledge technologies are available on different platforms. One of the possibilities is "cloud technologies". Cloud computing represents a wide scope for the development of computing network technologies [14]. The current trend between using and providing IT services is no longer a desktop solution. On the contrary, it is the provision of software as a service
(SaaS). The user only pays for what he uses. Frequency of use is also important. Currently, the user is allowed to use an IT solution, including hardware and other services.

Each construction project is in its own way unique. Despite the many specifics that construction projects have, certain processes and activities that are often repeated can be identified and their solution or procedure is very similar in many cases. As various authors point out independently [9], [15], many problems of knowledge management have already been explored in construction. There are several examples of how to proceed in a specific situation. There is a research group that highlights the importance of social processes, role models, knowledge management practices and their use and integration in building projects. Many of these solutions can be downloaded and applied as a model.

Knowledge management plays one of the key tasks in building project management. Efficient use of resources (material, work, time), efficient process management and automation of activities from design to implementation are one of the priorities for all participants involved in the construction project. At this level, the knowledge system can be perceived as a system that contains a wealth of information and data from all relevant areas that, by appropriate integration, generate knowledge and whose value to the participant is significant.

Behind the information system, it is also possible to find out BIM technologies. Creating an environment integrates data on possible space for simulation, automating processes and potentially finished solutions. Eastman et al. define BIM as a technology for causing and influencing a set of methods for manufacturing and testing building module methods [16]. According to the NBIMS vision, BIM indicates a tool that allows a process to be carried out to verify that standard mechanisms can be used for other equipment that contains all or other available information. The scope of BIM does not directly or indirectly affect all stakeholders. BIM is a fundamentally different way of producing and using data. The storage of data by central recipients has sought to selectively and potentially inform the applicable knowledge. This is possible because of [17]:

- Availability of tools to different suppliers ensures the robustness of the system,

- It is important to support the adaptability of the IT environment (that is, people, hardware and security),

- Better storage and connection features with BIM.

An important element or task is to create a knowledge base that often contains solutions that can be easily applied to the process to exploit the full 
potential of knowledge and information. Cost issue is important to create a knowledge database of costs for individual participants. The goal of all participants is to reduce construction time and minimize costs. Optimize flows and activities so that they ultimately represent costs for each participant at an acceptable level.

BIM (Building Information Modelling) is valuable tool in knowledge management and work with information [18]. Polish survey has shown that the BIM is common tool for design purposes and building. It is very important on maintenance of construction projects and results [19], [20]. BIM can be a very effective tool for some purposes in selected areas. According to several researches, approximately $30 \%$ of costs are lost in construction. This is mainly due to errors in coordination or also in the area of material waste. There is also a problem with work inefficiency.

The BIM technology is considered as a knowledge-based technology if it actively uses a smart feature library. It collects all the information about each part of the building in one place. The technology helps to integrate different aspects of the design effectively, reducing the risk of errors or irregularities and minimizing costs. The BIM object accurately defines the product, its properties, geometry (physical properties of the product), and contains visualization data that gives the object a recognizable appearance and functional information [21]. The smart issue library (building materials and works) should be automatically reflected in the bill of quantities and budget. The knowledge system consists of a function when a change of one element is recorded through a complex of linked elements that the system automatically modifies. It must be said that there are not many such solutions on the market.

Budget libraries appear to be a simple variant of smart budgets in design stage. These are interconnected to floor plan. If you change your floor plan, you'll see new calculations and budget adjustments. However, the results and the final budget for this solution are indicative.

Machine learning solutions in construction are generally at the beginning. The lack of a knowledge base of model projects is one of the reasons why this technology is still in its infancy.

Modular installation and design applications also use the knowledge base. There are several modules that can be combined based on predefined criteria. These modules contain specific parameters that draw information from the knowledge library.
Augmented, the virtual and artificial reality is another challenge in the construction industry. Digital collaboration and mobility is another trend. Digitization of project documentation is the basis. Print move to digital. Less paper means better results. This should be a challenge for the next generation. This also applies to other areas, not just construction. The basic principle of achieving this goal is the use of the ICT. The use of ICT is a major step towards aligning with this goal. The IoT, BIM and other technologies and their interrelationship and interconnection are shown in Figure 1. Effective results will be tolerated by the cooperation of these technologies. The first step is to gather knowledge. This is a prerequisite for the successful implementation and use of these technologies.

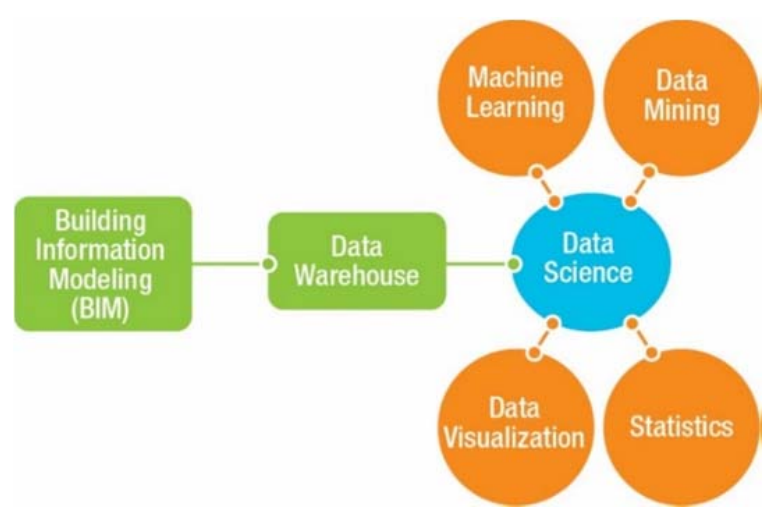

Figure 1. Knowledge-based technology scheme

Based on this literature review, knowledge-based systems and technology are challenge and a big opportunity in architecture, engineering and construction. These studies focused on the benefits of these knowledge-based technologies and systems. However, a general overview of the use of these technologies and systems is missing. This is true at least in the construction industry in Slovakia. Several researchers have addressed the partial use of individual technologies, but comprehensive research lacks, including the involvement of all major participants in construction projectss.

\section{Research Methodology}

Several knowledge-based systems and technology have been identified based on the literature review. As some partial studies have already indicated, their representation is not sufficient and satisfactory. These technologies are:

- Budget applications,

- BIM technology,

- Machine learning in construction,

- Applications for modular buildings in construction,

- Augmented, virtual intelligence. 
These technologies are the main point of interest in this research.

\subsection{Objective and Research Sample}

Based on previous identification of knowledgebased applications and technology in architecture, engineering and construction was set as a research problem. Research discusses the issue of a knowledge-based technology and systems used in the architecture, engineering and construction. The main research objective was to analyse a knowledge-based system used in architecture, engineering and construction and find the overview of exploitation level in this industry.

The research sample includes all significant participants of construction project from designer to investor. All answers of the respondents were achieved from construction projects in Slovakia. Totally, it was 153 construction projects in Slovakia. Description of research sample by the participant of the construction project is in Figure 2. Contractor and sub-contractor represent the biggest part of respondents, together $56 \%$. Other participants include investors, designers and an important part of the last phase of the construction project, is facility manager.

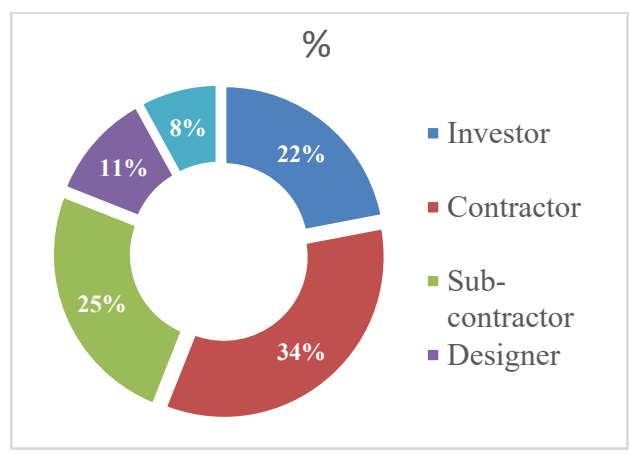

Figure 2. Research sample by participants of construction project

\subsection{Data Collection and Data Processing}

Data collection was done by an on-line questionnaire. Research questions were directed to the level of use of selected technologies. Respondents were asked to rate the use of selected technologies on the scale (from 1 - lowest exploitation level, to 5 - highest exploitation level). Based on the verification of IP repeatability, the originality of the responses was guaranteed. Subsequently, data were evaluated in MS Excel and Statistica 12. The suitability of the investigated sample was tested by statistical methods. Sampling was provided by databases of companies that carry out their business activities in the field of architecture, engineering and construction. The sampling was randomized from each group and reflected the relative proportion of individual participants by composition in the national economy. The rate of return was just over $7 \%$.

\section{Results and Discussion}

Knowledge-based technologies and systems are huge opportunities to increase the productivity of people in the industry. It is a good tool for increasing efficiency in managing individual construction projects. When identifying the research problem, it was assumed (also based on individual partial researches) that the use of knowledge-based technology and systems was at a relatively low level. This research has not refuted this assumption. On the contrary, as can be seen in detail in the following figure, the exploitation level of selected knowledgebased technology is at a relatively low level. Detailed results can be seen in the following figure (Fig. 3).

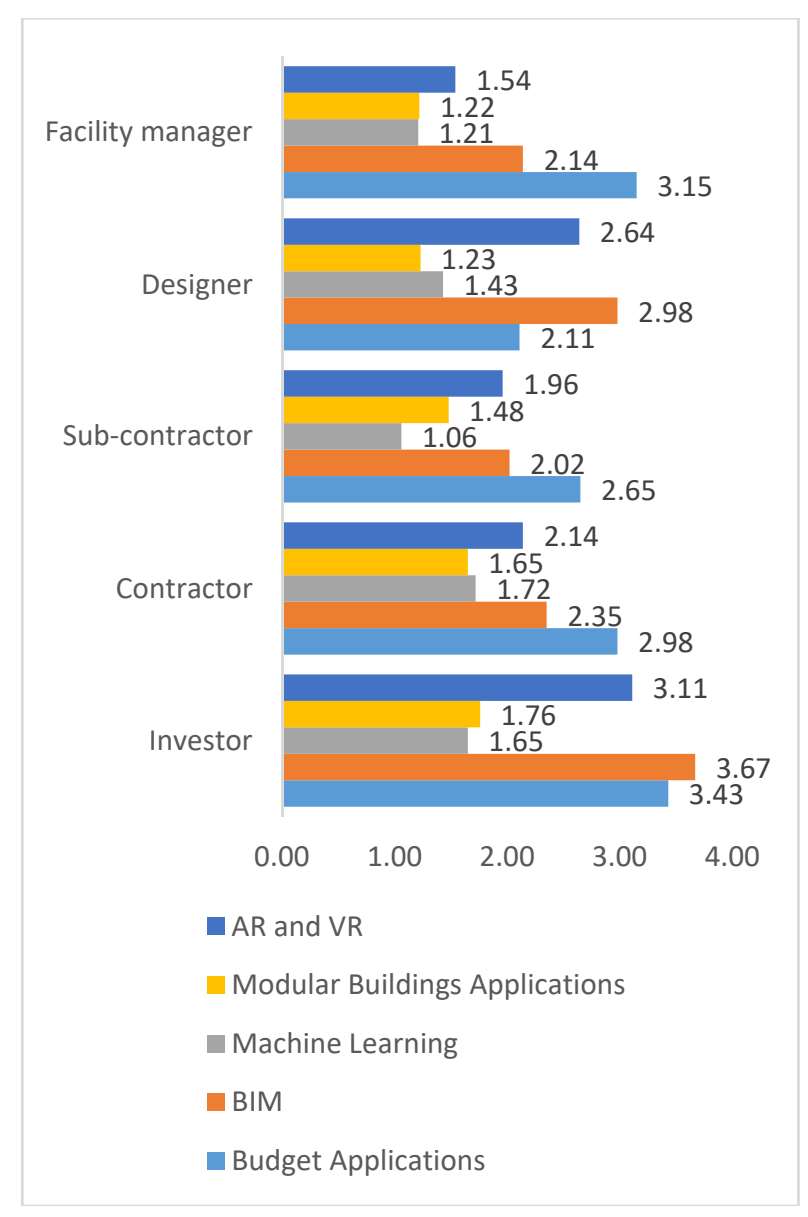

Figure 3. Results of research

(Exploitation level of knowledge-based technology)

In general, facility managers use the least knowledge of technology. It is a relatively interesting finding because even in this phase of the building's life cycle or construction project, there is a space to streamline processes and automate processes to save operating costs. On the contrary, most use is made by investors and contractors. Overall, however, the use of these technologies is not satisfactory. 
The results of individual technologies can be summarized as follows. The BIM technologies are most used by investors and designers. Also, there is a relatively higher use of facility managers. Conversely, contractors and sub-constructors still use this technology to a small extent. It is interesting to observe this knowledge and look for context. This may lead to the opinion that the BIM technology is largely being pushed by investors. If the investor is not interested in this form of data presentation, other participants use simpler but less sophisticated solutions. Conversely, contractors and subcontractors make little use of this tool. The implementation of the BIM across the construction industry is still at some moments more at the theoretical level than in practice.

Simple budgeting tools based on knowledge-based technology are used more strongly than the BIM, especially for a quick evaluation of the construction budget. This explains why it is used so heavily by investors in particular. However, it should be said that this tool is simple, and the result is not exactly accurate. Therefore, this tool still has great potential to be improved and perfected.

Interesting are the results of using $A R$ and $V R$ in CPM. Interesting are the results of using AR and VR in architecture, engineering and construction. These results said that this tool is used more often in planning than in the realization of the construction project itself. This can be due to several factors. On the one hand, this is less implementation of knowledge-based tools by contractors and subcontractors (such as the BIM technology, etc.). This group invests more in new technologies for the construction process, not for management. On the other hand, these are the possibilities and purpose of the results of augmented reality and virtual reality. Today it is an effective marketing tool and an interesting presentation of projects. Therefore, it is used to a greater extent by investors, who are often also in the role of developer and thus also the seller of the project. Similarly, there is close cooperation with designers where the main purpose is to make the presentation of the construction project more attractive.

\section{Conclusion}

The use of knowledge-based technology and systems is diverse. On the one hand, the results of the research can be considered as a better result than in comparison with partial research on a similar issue. Compared to them, it is possible to observe an increase in the use of knowledge-oriented technologies. In general, it's still the biggest potential for increasing in the implementation of knowledgebased tools in architecture, engineering and construction. The BIM technologies are increasingly implemented in the design and used in CP. This is especially true for larger projects and larger construction companies. However, the result is not at the level of theoretical knowledge in the field. For this reason, too, conditions should be established for better and faster implementation. Other instruments also do not reach half of their potential for use. There is a great deal of progress in research in the development of knowledge-based budget applications linked to the BIM technologies. To a large extent, there is an increase in both augmented and virtual reality. However, it should be noted here that it is always more for project presentation purposes than for construction management alone. This research pointed to the current situation of using selected knowledge-based technology and systems. In terms of exploiting these results, this can be taken as a trend and confirmation of assumption that globally the use of these technologies is at a relatively low level compared to their potential.

These results are general and describe the trend as it really is. From a scientific as well as a practical point of view, there is a project to move this research further. It is necessary to address the question why this is so as what the research shows. The outcome of the discussions describes certain factors of the use of knowledge-based systems and technology at a given level. However, this needs to be continued. To find dependencies among the factors that do these things. This research is also ongoing in the current time and focuses on finding answers and reasons for the relatively low use of these effective tools. 


\section{Acknowledgements}

"This work was supported by the Slovak Research and Development Agency under the contract no. APVV-170549”.

The paper presents a partial research results of project VEGA 1/0828/17 "Research and application of knowledge-based systems for modeling cost and economic parameters in Building Information Modeling”

\section{References}

[1]. Behun, M., Gavurova, B., Tkacova, A., \& Kotaskova, A. (2018). The impact of the manufacturing industry on the economic cycle of European Union countries. Journal of competitiveness, 10(1), 23.

[2]. Dupláková, D., Hatala, M., Duplák, J., Knapčíková, L., \& Radchenko, S. (2019). Illumination simulation of working environment during the testing of cutting materials durability. Ain Shams Engineering Journal, 10(1), 161-169.

[3]. Kol'veková, G., Liptáková, E., Štrba, L., Kršák, B., Sidor, C., Cehlár, M., ... \& Behún, M. (2019). Regional Tourism Clustering Based on the Three Ps of the Sustainability Services Marketing Matrix: An Example of Central and Eastern European Countries. Sustainability, 11(2), 400.

[4]. Gallaher, M. P., O'connor, A., Dettbarn, J. L., \& Gilday, L. T. (2004). Cost analysis of inadequate interoperability in the US capital facilities industry (NIST GCR 04-867). National Institute of Standards and Technology, Gaithersburg, MD, USA.

[5]. Sherehiy, B., \& Karwowski, W. (2006). Knowledge management for occupational safety, health, and ergonomics. Human Factors and Ergonomics in Manufacturing \& Service Industries, 16(3), 309-319.

[6]. Dugas, J., Seňová, A., Kršák, B., \& Ferencz, V. (2017). Implementation of business intelligence tools in companies. In New Trends in Process Control and Production Management (pp. 93-95). CRC Press.

[7]. Dingsøyr, T., \& Røyrvik, E. (2001, September). Skills management as knowledge technology in a software consultancy company. In International Workshop on Learning Software Organizations (pp. 96-103). Springer, Berlin, Heidelberg.

[8]. Siemieniuch, C. E., \& Sinclair, M. A. (1999). Aspects of knowledge lifecycle management in manufacturing industry, and their implications for organisational configurations. HUSAT Center University of Loughborough, UK.
[9]. Egbu, C. O., Sturgesand, J., \& Bates, B. (1999, September). Learning from knowledge management and trans-organisational innovations in diverse project management environments. In Proceedings of the 15th Annual conference of the association of researchers in construction management, Liverpool, Liverpool John Moores University.

[10]. Webb, S. P. (2017). Knowledge management: Linchpin of change. Routledge.

[11]. Wiig, K. M. (1999). What future knowledge management users may expect. Journal of knowledge management.

[12]. Carrillo, P. M., Anumba, C. J., \& Kamara, J. M. (2000). Knowledge management strategy for construction: key IT and contextual issues. Proceedings of CIT, 2000, 28-30.

[13]. Frey, R. S. (2001). Knowledge management, proposal development, and small businesses. Journal of Management Development, 20, 38-50.

[14]. Stark, R., Hayka, H., \& Langenberg, D. (2009). New potentials for virtual product creation by utilizing grid technology. CIRP annals, 58(1), 143-146.

[15]. Egbu, C. O., \& Botterill, K. (2003). Information technologies for knowledge management: their usage and effectiveness. Journal of Information Technology in Construction (ITcon), 7(8), 125-137.

[16]. Eastman, C. M., Eastman, C., Teicholz, P., Sacks, R., \& Liston, K. (2011). BIM handbook: A guide to building information modeling for owners, managers, designers, engineers and contractors. John Wiley \& Sons.

[17]. Peterson, F., Hartmann, T., Fruchter, R., \& Fischer, M. (2011). Teaching construction project management with BIM support: Experience and lessons learned. Automation in Construction, 20(2), 115-125.

[18]. Meadati, P. (2007). Integration of construction process documents into BIM. University of Nebraska, Lincoln.

[19]. Juszczyk, M., Výskala, M., \& Zima, K. (2015). Prospects for the use of BIM in Poland and the Czech Republic-Preliminary research results. Procedia Engineering, 123, 250-259.

[20]. CURT-Collaboration. (2004). Integrated Information and the Project Lifecycle in Building Design. Construction and Operation.

[21]. NBS 2016 What is Building Information Modelling (BIM)? Retrieved from: https://www.thenbs.com/knowledge/what-isbuilding-information-modelling-bim [accessed: 29 December 2019]. 